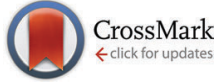

Cite this: Phys. Chem. Chem. Phys., 2015, 17, 23052

Received 29th May 2015, Accepted 5th August 2015 DOI: $10.1039 / c 5 c p 03112 e$

www.rsc.org/pccp

\section{Energy-dependent gas-phase fragmentation of fluorofullerene multiply charged anions (MCAs)}

\author{
Rolf W. Kirschbaum, ${ }^{a}$ Markus Hausmann, ${ }^{a}$ Olga V. Boltalina, ${ }^{b}$ Steven H. Strauss ${ }^{b}$ \\ and Thomas Drewello*a
}

Long-lived di- and trianions have been formed from fluorofullerenes in the gas phase by electrospray ionization. Fragmentation of multiply charged anions has been induced by multiple low-energy collisions. Two complementary dissociation experiments have been conducted. Firstly, unequivocal connectivity has been established between the precursor ion and the first and second generation of its product ions. Secondly, dianions have been studied in energy-resolved collisions, allowing the elucidation of the energetic demands of the dissociations. It was possible to study dianions with odd and even $F$ numbers, possessing even and odd electron configurations, respectively. The fragmentation behavior is governed by the electronic stability of the anionic protagonists, in that ions with the less stable odd-electron configuration dissociate into species with the more stable even-electron configuration. Dianions with an odd electron count release an $\mathrm{F}^{\bullet}$ atom to turn into an even electron system while retaining the charge state. Dianions with an even electron count undergo a more energy demanding charge separation reaction (Coulomb explosion) into an $\mathrm{F}^{-}$anion and an even electron monoanion. The studied trianions behave accordingly. $F_{2}$ loss is prominent only with monoanions within an even-to-even electron fragmentation cascade. The trianions are long-lived with lifetimes of at least $0.1 \mathrm{~s}$.

\section{Introduction}

Multiply charged anions (MCAs) are amongst the most elusive species in the gas phase. ${ }^{1-4}$ In solution or in the condensed phase MCAs are stabilized by interaction with suitable partners. However, when transferred into the gas phase, their stability entirely depends on the ability to accommodate several repulsive charges on one isolated entity. Some of the most common dianions in solution, such as $\mathrm{CO}_{3}{ }^{2-}$ or $\mathrm{SO}_{4}{ }^{2-}$, could not be generated in the gas phase. ${ }^{1-4}$ Those MCAs that showed sufficient stability have attracted attention and different approaches have been developed to study MCAs in the gas phase..$^{1-4}$ Stable gas phase dianions of fluorofullerenes have long been known and have been the topic of several investigations. ${ }^{5-14}$ Fluorofullerene dianions have been generated in various ways, including double electron attachment, ${ }^{5,14}$ electrochemical production followed by electrospray ionization-based transfer into the gas phase, ${ }^{13}$ electrospray ionization (ESI) from solutions doped with organic electron donor compounds, ${ }^{6,8}$ direct $\mathrm{ESI}^{9}$ and high-kinetic energy collisions, causing electron transfer to a monoanionic projectile fluorofullerene ion from gaseous sodium ${ }^{7}$ and other

\footnotetext{
${ }^{a}$ Physical Chemistry I, Department of Chemistry and Pharmacy, Friedrich-Alexander-University Erlangen-Nürnberg (FAU), Egerlandstraße 3, 91058 Erlangen, Germany. E-mail: thomas.drewello@fau.de

${ }^{b}$ Department of Chemistry, Colorado State University, Fort Collins, CO 80523, USA
}

gases. ${ }^{10-12}$ In the latter experiments it has been even possible to generate long-lived fluorofullerene trianions. ${ }^{15}$ In fluorofullerenes the combination of molecular size, the presence of strong covalent CC and CF bonds, as well as high electronegativity leads to a favorable situation in which the dianions are particularly stable. The fluorofullerene dianions have been found to be even more stable towards electron detachment than the corresponding monoanions. ${ }^{14}$ Fluorofullerenes possess a large second electron affinity $\left(E A_{2}\right)$. In the present context, the $E A_{2}$ is defined as the energy difference between mono- and dianions and positive values are assigned to thermochemically stable dianions. The $E A_{2}$ has been determined, for instance, by photoelectron spectroscopy as the adiabatic electron detachment energy of the dianion. For $\mathrm{C}_{60} \mathrm{~F}_{34}{ }^{2-}$ formed from $\mathrm{C}_{60} \mathrm{~F}_{36}$ an $E A_{2}\left(\mathrm{C}_{60} \mathrm{~F}_{34}\right)=2.50(5) \mathrm{eV}^{6}[2.4(1) \mathrm{eV}]^{8}$ and for $\mathrm{C}_{60} \mathrm{~F}_{46}{ }^{2-}$ formed from $\mathrm{C}_{60} \mathrm{~F}_{48}$ an $E A_{2}\left(\mathrm{C}_{60} \mathrm{~F}_{46}\right)=3.33(10) \mathrm{eV}^{6}$ $[3.2(1) \mathrm{eV}]^{8}$ have been determined. Compared with nonfluorinated fullerenes, these values are fairly high. The $E A_{2}$ of $\mathrm{C}_{60}$ has been established to be even negative ${ }^{16}$ and the $E A_{2}$ values of $\mathrm{C}_{76}, \mathrm{C}_{78}$ and $\mathrm{C}_{84}$ were measured to lie between 0.3 and $0.8 \mathrm{eV} \cdot{ }^{17,18}$ Of essential importance in the context of stability of the MCA towards electron detachment is the presence of a repulsive Coulomb barrier (RCB). ${ }^{14,19}$ The RCB arises as a combination of the binding interactions of the extra electron with the remainder of the MCAs in the short range and the charge repulsion in the long range, resulting in a potential, which may prevent spontaneous electron autodetachment. 
The even electron trianion $\mathrm{C}_{60} \mathrm{~F}_{47}{ }^{3-}$ is among the very few trianions that could be detected at all in the gas phase. It was generated in high-energy collisions of $\mathrm{C}_{60} \mathrm{~F}_{47}{ }^{-}$with $\mathrm{Na}$ as the collision gas by successive double electron attachment. While the third electron affinity of $\mathrm{C}_{60} \mathrm{~F}_{47}{ }^{3-}$ was calculated to be negative, leaving the trianion thermochemically unstable, the third electron is supposed to be trapped by a sufficiently high RCB. ${ }^{15}$

In the present investigation, di- and trianions are formed from fluorofullerenes by direct electrospray ionization. These stable and long-lived MCAs are activated by low-energy collisions and the resulting dissociation behavior is recorded in $\mathrm{MS}^{n}$ experiments using an ion trap mass spectrometer and establishing a fragmentation pedigree, providing unequivocal connectivity of the precursor and product ions of successive generations. The dianions with odd and even $\mathrm{F}$ numbers could be studied in a second collision experiment using a Qq-TOF mass spectrometer, allowing the study of energy-dependent dissociations of the dianionic precursor ions.

\section{Experimental section}

\section{Materials and reagents}

The fluorofullerene sample was of commercial origin and prepared by fluorination of fullerene with elemental fluorine. Similar samples have been the subject of earlier investigations into laser desorption/ionization and monoanion $\mathrm{CID},{ }^{20}$ determination of ionization energies by synchrotron radiation ${ }^{21}$ and ion formation by nanospray ionization. ${ }^{22}$

\section{Sample preparation}

Fluorinated fullerenes were dissolved either in acetonitrile (MeCN) or $N, N$-dimethylformamide (DMF), at a concentration of roughly $10^{-5} \mathrm{~mol} \mathrm{~L}{ }^{-1}$. Since fluorofullerenes decompose quickly in polar solvents, all samples were freshly prepared for consistent results. The samples were introduced into the ion source employing a single-syringe infusion pump (Cole Parmer, Vernon Hills, Illinois).

\section{MS $^{n}$ experiments}

$\mathrm{MS}^{n}$ experiments were carried out using an ESI-quadrupole ion trap instrument (esquire6000, Bruker) with the following settings. Sample flow rate, $4.0 \mu \mathrm{L} \mathrm{min}^{-1}$; nebulizer nitrogen pressure, $689 \mathrm{hPa}$; capillary entrance voltage, $+4000 \mathrm{~V}$; spray shield voltage, +3500 V; nitrogen dry gas temperature, $573 \mathrm{~K}$; dry gas flow rate, $5.0 \mathrm{~L} \mathrm{~min}^{-1}$; and the helium buffer/collision gas pressure was set to $4.0 \times 10^{-6} \mathrm{hPa}$ (the actual pressure in the analyzer is approximately 100 times higher ${ }^{23}$ ). Generally, the ion transfer settings vary due to spectrum tuning.

\section{Energy-dependent collision-induced dissociations (CID)}

Energy-dependent dissociation experiments were obtained using an electrospray quadrupole/time-of-flight (ESI-Qq-TOF) instrument (micrOTOF-Q II, Bruker). The following settings were applied. Flow rate, $3.0 \mathrm{~mL} \mathrm{~min}^{-1}$; nebulizer nitrogen pressure, $400 \mathrm{hPa}$; capillary entrance voltage, $+5000 \mathrm{~V}$; spray shield voltage, $+4500 \mathrm{~V}$; nitrogen dry gas temperature, $453 \mathrm{~K}$; and dry gas flow rate, $4.0 \mathrm{~L} \mathrm{~min}^{-1}$. Collision-induced dissociations ( $\mathrm{MS}^{2}$-CID) were conducted in the collision cell $\mathrm{q}$ located between $\mathrm{Q}$ and TOF, following mass selection and preceding the high-resolution daughter ion analysis in the TOF analyzer. Nitrogen $\left(\mathrm{N}_{2}\right)$ was used as the collision gas. The collision voltage was varied between 5 and $200 \mathrm{~V}$. The precursor ions were selected with an isolation width of $\mathrm{m} / \mathrm{z} 10$. The recorded spectra were processed using DataAnalysis 4.0 software (Bruker).

\section{Energy-dependent survival yields}

In order to compare the stability of the fluorofullerene dianions the survival yield $(S Y)^{24-27}$ of the precursor ion species was plotted as a function of the collision energy in the center-of-mass frame $\left(E_{\mathrm{COM}}\right)$, which is expressed by eqn (1) with the laboratoryframe collision energy $E_{\mathrm{LAB}}$, the mass of the collision-gas molecule $m_{\text {collision gas }}$ and the mass of the precursor ion $m_{\text {precursor ion. }}{ }^{24-34}$

$$
E_{\mathrm{COM}}=E_{\mathrm{LAB}} \times \frac{m_{\text {collision gas }}}{m_{\text {collision gas }}+m_{\text {precursor ion }}}
$$

All resulting sigmoidal curves can be described by a sigmoid function which is defined by eqn (2)

$$
S Y=\frac{a-b}{1+\mathrm{e}^{\left(x-x_{50}\right) c}}+b
$$

where $S Y$ is the survival yield (in percent), $x=E_{\mathrm{COM}}$ (in volts) and $a$, $b, c$ (in volts $\left.{ }^{-1}\right)$ and $x_{50}$ (in volts) are fitting parameters $\left(x_{50}=\right.$ $\left.E_{\mathrm{COM}, 50}\right)$. The fitting of the four parameters $a, b, c$ and $x_{50}$ was conducted applying a scaled Levenberg-Marquardt algorithm. The comparison of the precursor ion stabilities can be obtained by comparing $x_{50}$ at $S Y=50 \%$ which is the $E_{\mathrm{COM}}$ value at which the function has reached half of its maximum. ${ }^{26}$ The $E_{\mathrm{COM}}$ which is necessary for the effective fragmentation of the fluorofullerene dianions is rather high within the low-energy collision regime. Thus, scattering and electron loss lead to low precursor ion abundance and a low signal-to-noise ratio, even if the precursor ion intensity was sufficiently high at low collision energies (isolation without fragmentation). Both effects might result in an error that cannot be overcome by the present instrumental setup.

\section{Results and discussion}

Fig. 1 shows the negative-ion distribution obtained by electrospraying fluorofullerenes from two different solvents. Fig. 1A was obtained using MeCN as the solvent and Fig. 1B using DMF. Evidently, the nature of the solvent has a profound influence on the resulting ion distribution. ESI from MeCN (Fig. 1A) leads to a distribution in which the monoanions are more abundant than the dianions. Within the dianion population, species with an odd $\mathrm{F}$ number are more pronounced than the dianions with even F content. When sprayed from DMF, the situation is reversed with the dianions being more abundant than monoanions and dianions with even $\mathrm{F}$ content prevailing over those with odd $\mathrm{F}$ count. The electrochemical nature inherent to the ESI process plays an essential role in the ion formation under the present conditions..$^{9,22,35,36}$ However, 


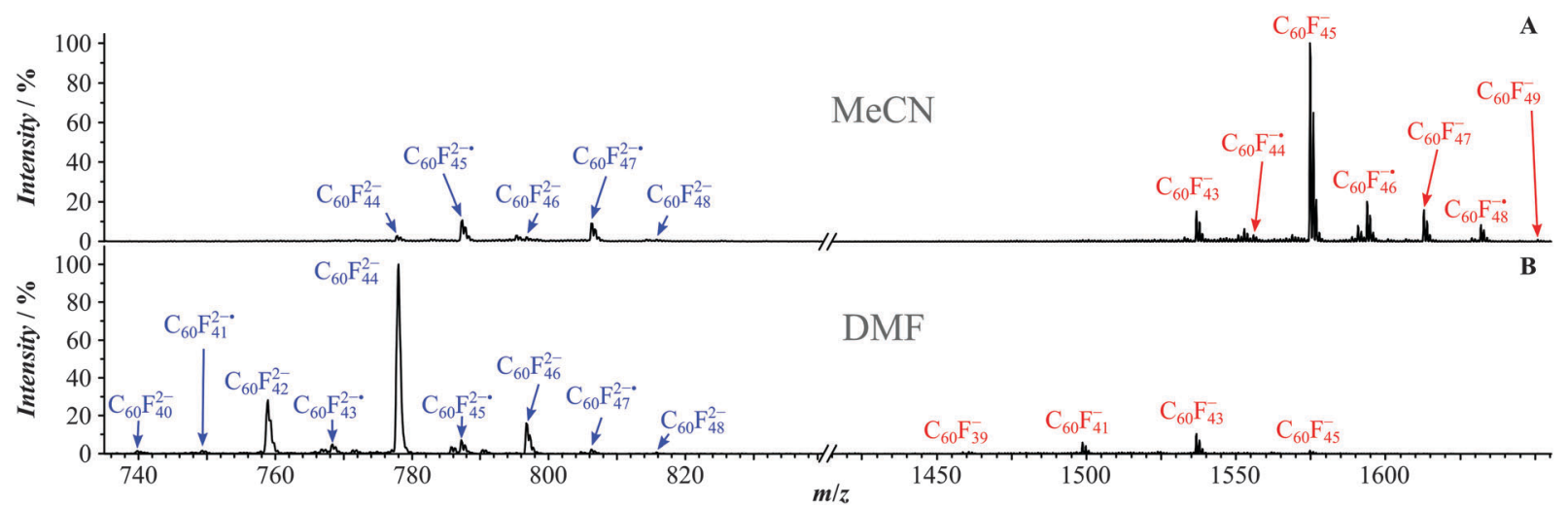

Fig. 1 ESI-QIT mass spectra of $\mathrm{C}_{60} \mathrm{~F}_{x}\left(c \approx 5 \times 10^{-5} \mathrm{~mol} \mathrm{~L}^{-1}\right)$ in $(\mathrm{A})$ acetonitrile (MeCN) and (B) $\mathrm{N}, \mathrm{N}$-dimethylformamide (DMF). The shown mass spectra represent the two extremes that were obtained in our experiments. Day-to-day variations showed less distinction but still the same tendencies.

several processes may influence the final appearance of the spectrum. The initial electrochemical reduction event is not the only relevant process. Decomposition of neutral species as well as dissociation of initially formed ions may contribute as well. It was shown, for instance, that the tailor-made formation of $\mathrm{C}_{60} \mathrm{~F}_{48}{ }^{2-}$ dianions by electrochemical reduction followed by ESI-based detection of possible ions would only result in the detection of $\mathrm{C}_{60} \mathrm{~F}_{47}{ }^{-}$monoanions. ${ }^{13}$ Equally, further electrochemical reduction of $\mathrm{C}_{60} \mathrm{~F}_{48}{ }^{2-}$ into $\mathrm{C}_{60} \mathrm{~F}_{48}{ }^{3-} \cdot$ would only lead to the detection of $\mathrm{C}_{60} \mathrm{~F}_{47}{ }^{2-} \cdot$ dianions formed by $\mathrm{F}^{-}$release from the trianion. ${ }^{13} \mathrm{C}_{60} \mathrm{~F}_{48}{ }^{2-}$ underwent complete dissociation into $\mathrm{F}^{-}$and $\mathrm{C}_{60} \mathrm{~F}_{47}{ }^{-}$. While the underlying processes that lead to the different ion distributions (Fig. 1) remain unresolved, the practical advantage has to be seen in the fact that dianions with both even and odd $\mathrm{F}$ content can be formed deliberately by simply changing the solvent. In this way, for the study of odd $\mathrm{F}$ content dianions MeCN was used as the solvent and for the study of dianions with even $\mathrm{F}$ count DMF was employed.

In Fig. 2 the fragmentation behavior is established by $\mathrm{MS}^{n}$ experiments, using $\mathrm{C}_{60} \mathrm{~F}_{n}{ }^{2-}$ dianions with odd $(n=47)$ and even

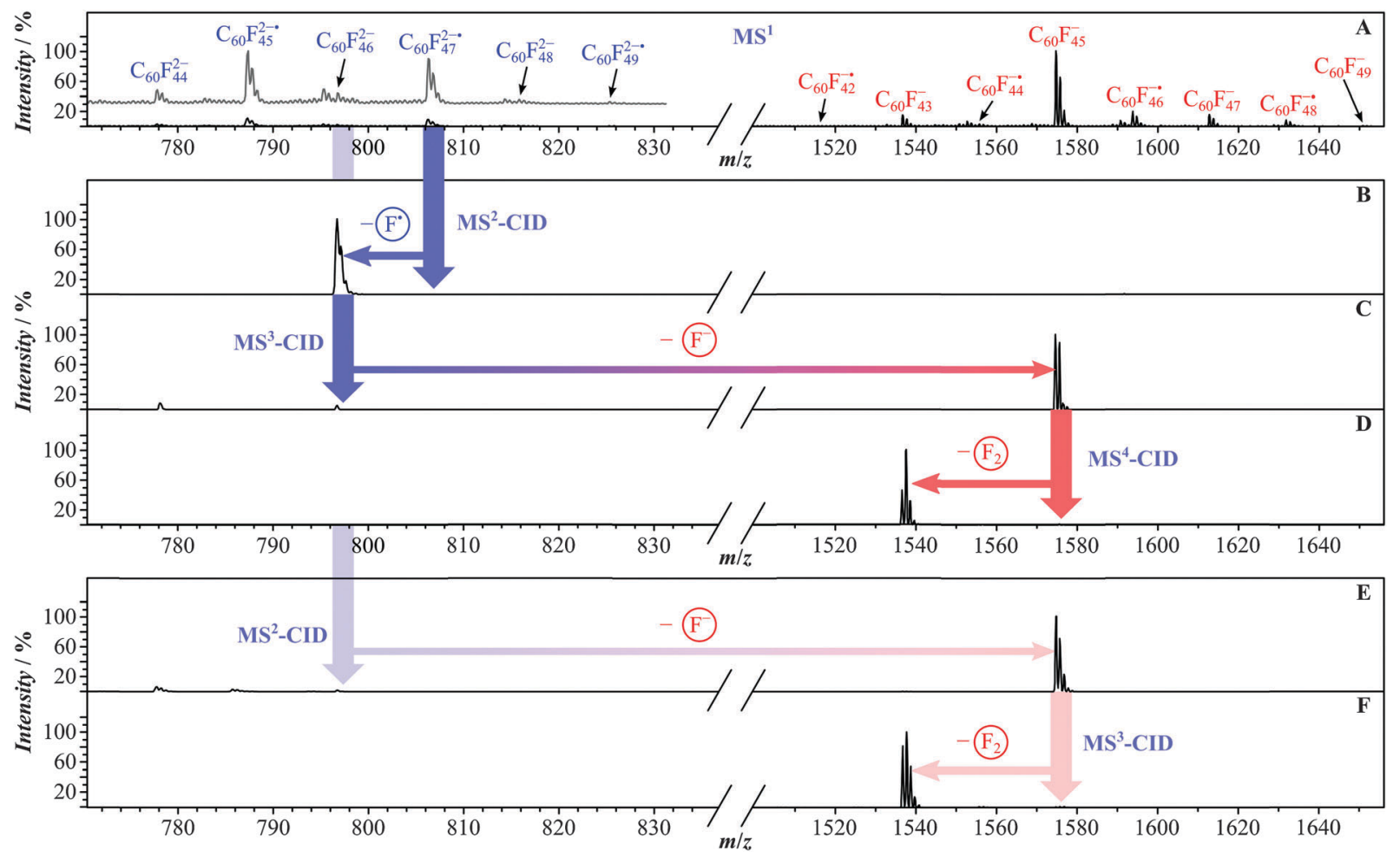

Fig. 2 (A) ESI-QIT mass spectrum of $\mathrm{C}_{60} \mathrm{~F}_{x}\left(c \approx 5 \times 10^{-5} \mathrm{~mol} \mathrm{~L} \mathrm{~L}^{-1}\right)$ in acetonitrile (MeCN). (B) $\mathrm{MS}^{2}-\mathrm{CID}$ of the odd electron species $\mathrm{C}_{60} \mathrm{~F}_{47}{ }^{2-} \cdot$ resulting in the loss of one neutral $\mathrm{F}^{\bullet}$ and the formation of the even electron species $\mathrm{C}_{60} \mathrm{~F}_{46}{ }^{2-}$. (C) $\mathrm{MS}^{3}-\mathrm{CID}$ of $\mathrm{C}_{60} \mathrm{~F}_{47}{ }^{2-} \cdot \mathrm{C}_{60} \mathrm{~F}_{46}{ }^{2-}$ resulting in a Coulomb explosion that affords $\mathrm{C}_{60} \mathrm{~F}_{45}{ }^{-}$and $\mathrm{F}^{-}$. (D) $\mathrm{MS}^{4}-\mathrm{CID}$ of $\mathrm{C}_{60} \mathrm{~F}_{47}{ }^{2-} \cdot \rightarrow \mathrm{C}_{60} \mathrm{~F}_{46}{ }^{2-} \rightarrow \mathrm{C}_{60} \mathrm{~F}_{45}{ }^{-}$resulting in a neutral species loss of $\mathrm{F}_{2}$ and the formation of $\mathrm{C}_{60} \mathrm{~F}_{43}{ }^{-}$. (E) $\mathrm{MS}^{2}-\mathrm{CID}$ of the even-electron species $\mathrm{C}_{60} \mathrm{~F}_{46}{ }^{2-}$ resulting in the formation of $\mathrm{C}_{60} \mathrm{~F}_{45}{ }^{-}$and $\mathrm{F}^{-}$(Coulomb explosion). (F) $\mathrm{MS}^{3}-\mathrm{CID}$ of $\mathrm{C}_{60} \mathrm{~F}_{46}{ }^{2-} \rightarrow \mathrm{C}_{60} \mathrm{~F}_{45}{ }^{-}$leading to the formation of $\mathrm{C}_{60} \mathrm{~F}_{43}{ }^{-}$by the release of the neutral species $\mathrm{F}_{2}$. 
F content $(n=46)$ as the initial precursor ions. The fragmentation pattern is straightforward and clean. $\mathrm{C}_{60} \mathrm{~F}_{47}{ }^{2-} \cdot$ (Fig. 2A) shows the loss of an $\mathrm{F}^{\bullet}$ atom leading to the $\mathrm{C}_{60} \mathrm{~F}_{46}{ }^{2-}$ dianion with even F content (Fig. 2B). Selection and further activation of the latter ion $\left(\mathrm{MS}^{3}\right.$ ) lead to a Coulomb explosion into $\mathrm{F}^{-}$(below the detection limit of the ion trap) and $\mathrm{C}_{60} \mathrm{~F}_{45}{ }^{-}$(Fig. 2C). A reaction that leads to separation of equal charges is here referred to as a Coulomb explosion. ${ }^{37}$ The alternative reaction path of neutral losses into smaller dianions occurs for the $\mathrm{C}_{60} \mathrm{~F}_{46}{ }^{2-}$ dianion only to a very minor extent, producing a minute amount of $\mathrm{C}_{60} \mathrm{~F}_{44}{ }^{2-}$ product ion by $\mathrm{F}_{2}$ loss. In the final $\mathrm{MS}^{4}$ experiment (Fig. 2D), the $\mathrm{C}_{60} \mathrm{~F}_{45}$ monoanion undergoes $\mathrm{F}_{2}$ loss to produce $\mathrm{C}_{60} \mathrm{~F}_{43}{ }^{-}$. This fragmentation behavior seems to be governed by the tendency to produce product ions of enhanced electronic stability, which are characterized by an even electron count, signifying the closed shell system. For dianions the even electron configuration is reached with an even-numbered $\mathrm{F}$ atom content, whereas mono- and trianions would require an odd $\mathrm{F}$ number. The starting $\mathrm{C}_{60} \mathrm{~F}_{47}{ }^{2-} \bullet$ dianion does not undergo Coulomb explosion by $\mathrm{F}^{-}$loss, as the complementary fragment ion $\mathrm{C}_{60} \mathrm{~F}_{46}{ }^{-\bullet}$ would be an odd electron ion and as such is less stable. Instead the loss of neutral $\mathrm{F}^{\bullet}$ leads to the even electron ion $\mathrm{C}_{60} \mathrm{~F}_{46}{ }^{2-}$. All further fragmentations would start from an even-electron ion and lead to even electron fragment ions. In Fig. $2 \mathrm{~A}, \mathrm{E}$ and $\mathrm{F}$, the $\mathrm{MS}^{n}$ experiments are shown, starting with the $\mathrm{C}_{60} \mathrm{~F}_{46}{ }^{2-}$ dianion generated in the ESI source to allow comparison with the $\mathrm{C}_{60} \mathrm{~F}_{46}{ }^{2-}$ dianion produced from $\mathrm{C}_{60} \mathrm{~F}_{47}{ }^{2-} \bullet$ by CID in the ion trap (Fig. 2A-D). Both dianions show essentially the same dissociation behavior. An earlier odd/ even alternation was discovered in dissociative electron capture experiments with fluorinated fullerene cations. ${ }^{11}$ It was found that the formation of odd F-containing dianions was accompanied by the preferred loss of just one $\mathrm{F}^{\bullet}$ atom, while even $\mathrm{F}$-containing dianions were preferably accompanied by the loss of two $\mathrm{F}$ atoms. Both the present and earlier ${ }^{11}$ odd/even alternation are driven by the enhanced stability of the even electron system.

In the next set of experiments, the fragmentation behavior of the fluorofullerene dianions is studied in energy-dependent collision-induced dissociations employing a Qq-TOF instrument. In these experiments, the dianion of interest is selected using a quadrupole mass filter and allowed to enter a quadrupole that functions as a collision cell at a well-defined kinetic energy, which is varied stepwise between $z \times 5 \mathrm{eV}$ and $z \times 200 \mathrm{eV}$ ( $z$ being the charge number of the precursor ion). During the flight through the collision cell quadrupole, the projectile precursor ion experiences multiple low-energy collision events. The internal energy content of the ion increases and fragmentation leads to product ions. The product ions may also be activated and undergo further dissociations. By increasing the kinetic energy of the incoming ion, the extent of fragmentation can be increased and a cascade of successive reactions may be extended. After the collision cell, the ion distribution is recorded using a TOF analyzer. The plot of the relative ion distribution as a function of collision energy is commonly referred to as a breakdown graph. The breakdown graph provides insight into the energetic demands of the dissociation and may also reveal the occurrence of parallel $v s$. successive reaction pathways. ${ }^{38}$ We note that CID using collisions in the ion trap would not result in a similar extent of fragmentation as only the parent ions are activated and not the resulting product ions. ${ }^{39}$ Fig. 3A displays the breakdown graphs of the (odd electron) $\mathrm{C}_{60} \mathrm{~F}_{45}{ }^{2-} \cdot$ dianion. Upon increasing collision energy, $\mathrm{F}^{\bullet}$ atom loss leads to the formation of the (even electron) $\mathrm{C}_{60} \mathrm{~F}_{44}{ }^{2-}$ dianion, which upon further increase of the collision energy undergoes a Coulomb explosion into the (even electron) $\mathrm{C}_{60} \mathrm{~F}_{43}{ }^{-}$monoanion, which undergoes successive $\mathrm{F}_{2}$ losses into smaller even-electron monoanions. Fig. 3B shows the corresponding breakdown graph of the $\mathrm{C}_{60} \mathrm{~F}_{44}{ }^{2-}$ dianion. It is confirmed that the Coulomb explosion of the even electron dianion requires roughly twice (factor 5/3) the collision energy needed for the $\mathrm{F}^{\bullet}$ atom loss from the less favored odd electron dianion. Moreover, comparing Fig. $3 \mathrm{~A}$ and $\mathrm{B}$, the almost perfect match of various successive reactions in both figures is apparent. The sequential reactions start in both cases with the $\mathrm{C}_{60} \mathrm{~F}_{44}{ }^{2-}$ dianion, in one case it is generated in the ESI source (Fig. 3B) and in the other case by CID from $\mathrm{C}_{60} \mathrm{~F}_{45}{ }^{2-} \cdot$ (Fig. 3A). Evidently, both processes afford here dianions with very similar internal energy content.

In the following, we discuss the energy-dependent dissociations of different dianionic precursor ions featuring even and odd F content. The decline of the precursor ion abundance is displayed as a function of $E_{\mathrm{COM}}$ (Fig. 4). The collision energy at which the precursor ion has declined to half of its initial abundance is referred to as $x_{50}$ value $\left(=E_{\mathrm{COM}, 50}\right)$ and is taken as a measure of the relative stability of the ions in the collision experiment. The dianions $\mathrm{C}_{60} \mathrm{~F}_{n}{ }^{2-\bullet}$ with $n=45,47$ and 49 of odd electron amount are compared to the even electron dianions $\mathrm{C}_{60} \mathrm{~F}_{n}{ }^{2-}$ with $n=42,44$ and 46. The odd electron dianions show an $x_{50}$ value of $1.6 \mathrm{eV}$ for
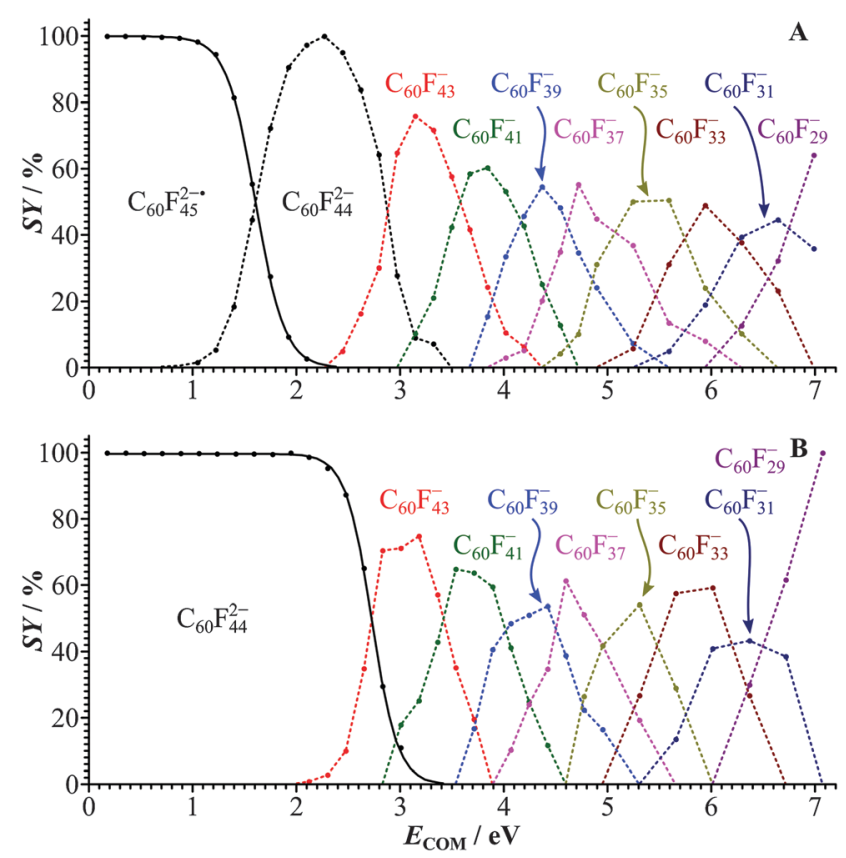

Fig. 3 Survival yield (SY) vs. collision energy in the center-of-mass frame $\left(E_{\mathrm{COM}}\right)$ measured using an ESI-Qq-TOF mass spectrometer. (A) Odd electron precursor ion species: $\mathrm{C}_{60} \mathrm{~F}_{45}{ }^{2-} \bullet$. (B) Even electron precursor ion species: $\mathrm{C}_{60} \mathrm{~F}_{44}{ }^{2-}$ 


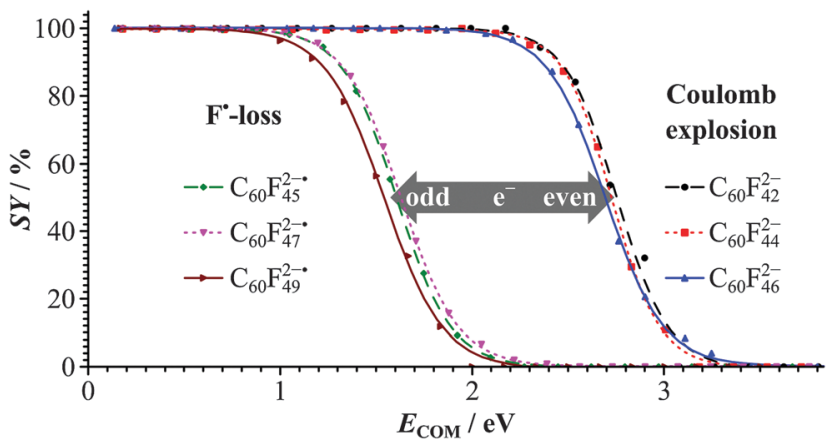

Fig. 4 Survival yield (SY) vs. collision energy in the center-of-mass frame $\left(E_{\mathrm{CO}}\right)$ of even electron (EE) and odd electron (OE) fluorofullerene dianions measured using an ESI-Qq-TOF mass spectrometer.

the $\mathrm{F}^{\bullet}$ loss und the even electron dianions display an $x_{50}$ value of $2.7 \mathrm{eV}$ for the $\mathrm{F}^{-}$loss (Coulomb explosion). It is confirmed that the even electron dianions are more stable, resisting the Coulomb explosion up to an $E_{\mathrm{COM}}$ that is by a factor of $5 / 3$ higher than the $E_{\mathrm{COM}}$ required for the less stable odd electron dianions to undergo $\mathrm{F}^{\bullet}$ loss. The driving force facilitating the $\mathrm{F}^{\bullet}$ loss seems to result from the transition of odd to even electron configuration in the dianion.

The final set of experiments is again conducted using the ESI-ion trap instrument, with which the detection of triply charged anions of the form $\mathrm{C}_{60} \mathrm{~F}_{n}{ }^{3-}$ with $n=43$ and 45 was possible. The three extra electrons reside on a fluorofullerene molecule that has undergone the formal loss of one $\mathrm{F}^{\bullet}$ atom to obtain an odd $\mathrm{F}$ number. The resulting trianion is of even electron count and thus the more stable variant to the true molecular trianion, which could not be observed in these experiments. Trianions of observed type have been produced before by high-energy collision-induced double electron attachment from the corresponding monoanion. ${ }^{15}$ While the third electron affinity has been predicted to be negative, so that the trianion is thermochemically unstable, the existence of a substantial RCB of around $1 \mathrm{eV}$ has been estimated to prevent electron loss from the trianion. ${ }^{15}$ In the initial experiment, the time between the collision event that formed the trianion and its detection limited its lifetime to a maximum of about $10 \mu \mathrm{s}$. In the present study the trianions are formed by direct ESI using an ion trap for detection, which translates into a lifetime of at least $0.1 \mathrm{~s}$, extending the lifetime of the trianions by five orders of magnitude and confirming that these trianions are in fact long-lived.

The fragmentation behavior of the $\mathrm{C}_{60} \mathrm{~F}_{45}{ }^{3-}$ trianion can be predicted from the dianion behavior. An odd electron trianion (which was not observed here) would be expected to release an $\mathrm{F}^{\bullet}$ atom to turn into an even electron trianion. The even electron trianion would be expected to undergo a Coulomb explosion by $\mathrm{F}^{-}$loss to produce the even electron dianion. This is exactly the behavior that has been observed in Fig. 5 . The $\mathrm{MS}^{2}$ of $\mathrm{C}_{60} \mathrm{~F}_{45}{ }^{3-}$ shows a Coulomb explosion into the $\mathrm{F}^{-} / \mathrm{C}_{60} \mathrm{~F}_{44}{ }^{2-}$ ion pair and $\mathrm{MS}^{3}$ of the $\mathrm{C}_{60} \mathrm{~F}_{44}{ }^{2-}$ dianion shows a second, successive Coulomb explosion into $\mathrm{F}^{-} / \mathrm{C}_{60} \mathrm{~F}_{43}{ }^{-}$. Unfortunately, the trianions could not be generated on the ESI-Qq-TOF instrument to allow energy-resolved dissociations to be conducted.

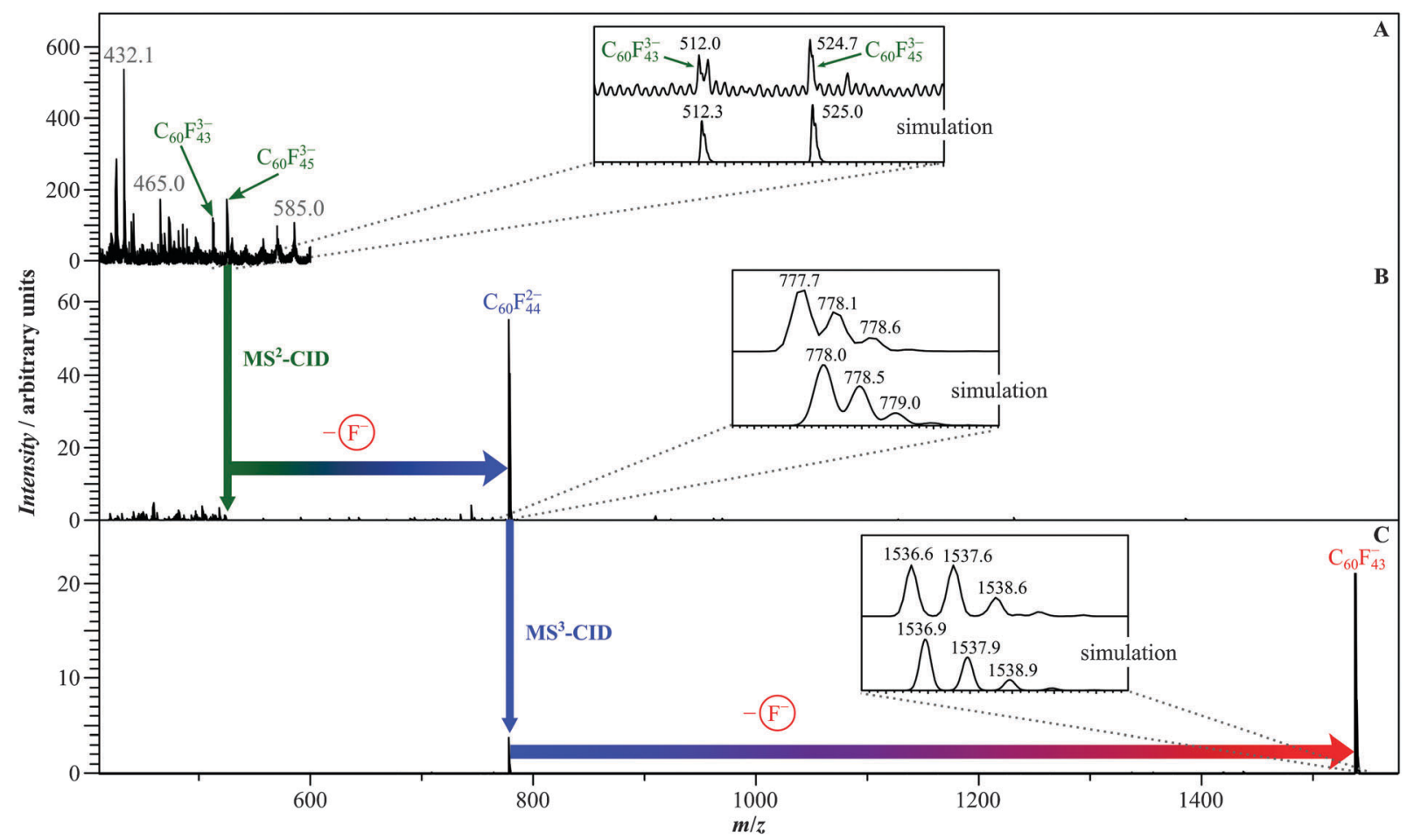

Fig. 5 (A) ESI-QIT mass spectrum of $\mathrm{C}_{60} \mathrm{~F}_{x}\left(c \approx 5 \times 10^{-5} \mathrm{~mol} \mathrm{~L}^{-1}\right)$ in acetonitrile $(\mathrm{MeCN})$. (B) $\mathrm{MS}^{2}-\mathrm{CID}$ of $\mathrm{C}_{60} \mathrm{~F}_{45}{ }^{3-}$ resulting in the formation of $\mathrm{C}_{60} \mathrm{~F}_{44}{ }^{2-}$ and $\mathrm{F}^{-}$(Coulomb explosion). (C) $\mathrm{MS}^{3}-\mathrm{CID}$ of $\mathrm{C}_{60} \mathrm{~F}_{44}{ }^{2-}$ resulting in the formation of $\mathrm{C}_{60} \mathrm{~F}_{43}{ }^{-}$and $\mathrm{F}^{-}$(Coulomb explosion). 


\section{Conclusions}

The fragmentation dynamics of fluorofullerene di- and trianions is governed by their electronic stability. The driving force for the dissociations is the formation of ions with an even electron count and closed shell electron configuration. Uneven electron MCAs show the loss of an $\mathrm{F}^{\bullet}$ atom to turn into an even electron MCA. Even electron MCAs undergo $\mathrm{F}^{-}$anion loss in a Coulomb explosion, reducing the charge state of the MCA by one. The $\mathrm{F}^{\bullet}$ loss proceeds from the less stable electron configuration and is less energy demanding than the Coulomb explosion.

\section{Acknowledgements}

The authors thank the Deutsche Forschungsgemeinschaft (DFG) SFB 953 "Synthetic Carbon Allotropes" for financial support.

\section{References}

1 X.-B. Wang and L.-S. Wang, Photoelectron Spectroscopy of Multiply Charged Anions, Annu. Rev. Phys. Chem., 2009, 60, 105-126.

2 W. E. Boxford and C. E. H. Dessent, Probing the Intrinsic Features and Environmental Stabilization of Multiply Charged Anions, Phys. Chem. Chem. Phys., 2006, 8, 5151-5165.

3 S. Feuerbacher and L. S. Cederbaum, Stable and Long-Lived Trianions in the Gas Phase, J. Phys. Chem. A, 2005, 109, 11401-11406.

4 A. Dreuw and L. S. Cederbaum, Multiply Charged Anions in the Gas Phase, Chem. Rev., 2001, 102, 181-200.

5 R. F. Tuktarov, R. V. Khatymov, V. Y. Markov, N. A. Romanova and M. V. Muftakhov, Formation of Doubly Charged Negative Ions Under the Conditions of the Resonant Electron Capture by Fluorofullerenes, JETP Lett., 2013, 96, 664-667.

6 X.-B. Wang, C. Chi, M. Zhou, I. V. Kuvychko, K. Seppelt, A. A. Popov, S. H. Strauss, O. V. Boltalina and L.-S. Wang, Photoelectron Spectroscopy of $\mathrm{C}_{60} \mathrm{~F}_{n}{ }^{-}$and $\mathrm{C}_{60} \mathrm{~F}_{m}{ }^{2-}(n=17$, $33,35,43,45,47 ; m=34,46)$ in the Gas Phase and the Generation and Characterization of $C_{1}-\mathrm{C}_{60} \mathrm{~F}_{47}{ }^{-}$and $D_{2}-\mathrm{C}_{60} \mathrm{~F}_{44}$ in Solution, J. Phys. Chem. A, 2010, 114, 1756-1765.

7 A. V. Streletskiy, P. Hvelplund, S. B. Nielsen, B. Liu, S. Tomita, A. A. Goryunkov and O. V. Boltalina, Differences in Electronic Properties of Fluorinated and Trifluoromethylated Fullerenes Revealed by Their Propensity for Dianion Formation, J. Chem. Phys., 2006, 124(144306), 1-4.

8 I. N. Ioffe, S. M. Avdoshenko, O. V. Boltalina, L. N. Sidorov, K. Berndt and J. M. Weber, Mass Spectrometry, Photoelectron Spectroscopy, and Quantum Chemical Studies of Fluorofullerene Dianions, Int. J. Mass Spectrom., 2005, 243, 223-230.

9 T. Drewello, H. Frauendorf, R. Herzschuh, A. A. Goryunkov, S. H. Strauss and O. V. Boltalina, The Formation of Long-Lived Fluorofullerene Dianions by Direct Electrospray Ionization, Chem. Phys. Lett., 2005, 405, 93-96.

10 A. A. Tuinman and R. N. Compton, Doubly Charged Negative Ions via Charge-Exchange Collisions: $\mathrm{C}_{60} \mathrm{~F}_{36}{ }^{-}+\mathrm{CH}_{4} \rightarrow \mathrm{C}_{60} \mathrm{~F}_{36}{ }^{2-}$ $+\mathrm{CH}_{4}{ }^{+}$, Phys. Rev. A: At., Mol., Opt. Phys., 2002, 65(052724), 1-3.
11 O. V. Boltalina, P. Hvelplund, T. J. D. Jørgensen, M. C. Larsen, M. O. Larsson and D. A. Sharoitchenko, Electron Capture by Fluorinated Fullerene Anions in Collisions with Xe Atoms, Phys. Rev. A: At., Mol., Opt. Phys., 2000, 62(023202), 1-7.

12 O. V. Boltalina, P. Hvelplund, M. C. Larsen and M. O. Larsson, Electron Capture by $\mathrm{C}_{60} \mathrm{~F}_{35}{ }^{-}$in Collisions with Atomic and Molecular Targets, Phys. Rev. Lett., 1998, 80, 5101-5104.

13 F. Zhou, G. J. Van Berkel and B. T. Donovan, ElectronTransfer Reactions of $\mathrm{C}_{60} \mathrm{~F}_{48}, \mathrm{~J}$. Am. Chem. Soc., 1994, 116, 5485-5486.

14 C. Jin, R. L. Hettich, R. N. Compton, A. Tuinman, A. DerecskeiKovacs, D. S. Marynick and B. I. Dunlap, Attachment of Two Electrons to $\mathrm{C}_{60} \mathrm{~F}_{48}$ : Coulomb Barriers in Doubly Charged Anions, Phys. Rev. Lett., 1994, 73, 2821-2824.

15 O. V. Boltalina, A. V. Streletskii, I. N. Ioffe, P. Hvelplund, B. Liu, S. B. Nielsen and S. Tomita, Formation of Long-Lived Fluorofullerene Trianions in Collisions with Na, J. Chem. Phys., 2005, 122(021102), 1-3.

16 C. Yannouleas and U. Landman, Stabilized-Jellium Description of Neutral and Multiply Charged Fullerenes $\mathrm{C}_{60}{ }^{x \pm}$, Chem. Phys. Lett., 1994, 217, 175-185.

17 O. T. Ehrler, F. Furche, J. M. Weber and M. M. Kappes, Photoelectron Spectroscopy of Fullerene Dianions $\mathrm{C}_{76}{ }^{2-}$, $\mathrm{C}_{78}{ }^{2-}$, and $\mathrm{C}_{84}{ }^{2-}$, J. Chem. Phys., 2005, 122(094321), 1-8.

18 X.-B. Wang, H.-K. Woo, J. Yang, M. M. Kappes and L.-S. Wang, Photoelectron Spectroscopy of Singly and Doubly Charged Higher Fullerenes at Low Temperatures: $\mathrm{C}_{76}{ }^{-}, \mathrm{C}_{78}{ }^{-}, \mathrm{C}_{84}{ }^{-}$and $\mathrm{C}_{76}{ }^{2-}, \mathrm{C}_{78}{ }^{2-}, \mathrm{C}_{84}{ }^{2-}$, J. Phys. Chem. C, 2007, 111, 17684-17689.

19 A. Dreuw and L. S. Cederbaum, Nature of the Repulsive Coulomb Barrier in Multiply Charged Negative Ions, Phys. Rev. A: At., Mol., Opt. Phys., 2000, 63(012501), 1-13.

20 L. Käseberg, R. Herzschuh, S. Suslov, O. V. Boltalina, R. Cozzolino, O. Belgacem and T. Drewello, Laser Desorption/Ionisation of Fluorinated Fullerenes, Eur. J. Mass Spectrom., 1997, 3, 407-414.

21 H. Steger, U. Mische, W. Kamke, A. Ding, M. FieberErdmann and T. Drewello, Ionisation and Fragmentation Dynamics of Highly Fluorinated Fullerenes $\mathrm{C}_{60} \mathrm{~F}_{46,48}$ and $\mathrm{C}_{70} \mathrm{~F}_{54,56}$ after Excitation with Synchrotron Radiation, Chem. Phys. Lett., 1997, 276, 39-46.

22 M. P. Barrow, X. Feng, J. I. Wallace, O. V. Boltalina, R. Taylor, P. J. Derrick and T. Drewello, Characterization of Fullerenes and Fullerene Derivatives by Nanospray, Chem. Phys. Lett., 2000, 330, 267-274.

23 R. M. Danell, A. S. Danell, G. L. Glish and R. W. Vachet, The Use of Static Pressures of Heavy Gases Within a Quadrupole Ion Trap, J. Am. Soc. Mass Spectrom., 2003, 14, 1099-1109.

24 Á. Kuki, L. Nagy, A. Memboeuf, L. Drahos, K. Vékey, M. Zsuga and S. Kéki, Energy-Dependent CollisionInduced Dissociation of Lithiated Polytetrahydrofuran: Effect of the Size on the Fragmentation Properties, J. Am. Soc. Mass Spectrom., 2010, 21, 1753-1761.

25 T. M. Kertesz, L. H. Hall, D. W. Hill and D. F. Grant, $\mathrm{CE}_{50}$ : Quantifying Collision Induced Dissociation Energy for Small Molecule Characterization and Identification, J. Am. Soc. Mass Spectrom., 2009, 20, 1759-1767. 
26 A. Memboeuf, A. Nasioudis, S. Indelicato, F. Pollreisz, Á. Kuki, S. Kéki, O. F. van den Brink, K. Vékey and L. Drahos, Size Effect on Fragmentation in Tandem Mass Spectrometry, Anal. Chem., 2010, 82, 2294-2302.

27 X. Guo, M. C. Duursma, P. G. Kistemaker, N. M. M. Nibbering, K. Vékey, L. Drahos and R. M. A. Heeren, Manipulating Internal Energy of Protonated Biomolecules in Electrospray Ionization Fourier Transform Ion Cyclotron Resonance Mass Spectrometry, J. Mass Spectrom., 2003, 38, 597-606.

28 K. Vékey, Internal Energy Effects in Mass Spectrometry, J. Mass Spectrom., 1996, 31, 445-463.

29 N. Vinokur and V. Ryzhov, Using Collision-Induced Dissociation with Corrections for the Ion Number of Degrees of Freedom for Quick Comparisons of Relative Bonding Strength, J. Mass Spectrom., 2004, 39, 1268-1274.

30 C. Lifshitz, Kinetic Shifts, Eur. J. Mass Spectrom., 2002, 8, 85-98.

31 A. K. Shukla and J. H. Futrell, Tandem Mass Spectrometry: Dissociation of Ions by Collisional Activation, J. Mass Spectrom., 2000, 35, 1069-1090.

32 J. M. Daniel, S. D. Friess, S. Rajagopalan, S. Wendt and R. Zenobi, Quantitative Determination of Noncovalent Binding Interactions Using Soft Ionization Mass Spectrometry, Int. J. Mass Spectrom., 2002, 216, 1-27.

33 Y.-L. Chen, J. M. Campbell, B. A. Collings, L. Konermann and D. J. Douglas, Stability of a Highly Charged Noncovalent
Complex in the Gas Phase: Holomyoglobin, Rapid Commun. Mass Spectrom., 1998, 12, 1003-1010.

34 S. Jung, J. D. van Paauwe, P. D. W. Boyd and S. K. Shin, Noncovalent Endo-Binding of Fullerenes to Diprotonated Bisporphyrins, Phys. Chem. Chem. Phys., 2011, 13, 20248-20254.

35 G. J. Van Berkel and F. Zhou, Observation of Gas-Phase Molecular Dications Formed from Neutral Organics in Solution via The Controlled-Current Electrolytic Process Inherent to Electrospray, J. Am. Soc. Mass Spectrom., 1996, 7, 157-162.

36 G. J. Van Berkel and F. Zhou, Electrospray as a ControlledCurrent Electrolytic Cell: Electrochemical Ionization of Neutral Analytes for Detection by Electrospray Mass Spectrometry, Anal. Chem., 1995, 67, 3958-3964.

37 T. Drewello, C. B. Lebrilla, H. Schwarz and T. Ast, Charge Separation (Coulomb Explosion) Processes of Doubly Charged Cations of Sandwich Compounds in the Gas Phase: Evidence for the Junction of two $\mathrm{C}_{5} \mathrm{H}_{5}$ Units, J. Organomet. Chem., 1988, 339, 333-338.

38 R. Herzschuh and T. Drewello, The Fragmentation Dynamics of Small $\mathrm{Cs}(\mathrm{CsI})_{n}{ }^{+}$Cluster Ions Under Low-Energy Multiple Collision Conditions, Int. J. Mass Spectrom., 2004, 233, 355-359.

39 Á. Révész, T. A. Rokob, G. Maász, L. Márk, H. Hevér, L. Drahos and K. Vékey, Fragmentation, Structure, and Energetics of Small Sodium Formate Clusters: Evidence for Strong Influence of Entropic Effects, Int. J. Mass Spectrom., 2013, 354-355, 292-302. 